Logos Universality Mentality Education Novelty, Section: Social Sciences

ISSN: $2284-5747$ (print), ISSN: $2284-5747$

(electronic)

Covered in: CEEOL, Index Copernicus, Ideas

RePeC, EconPapers, Socionet

\title{
VALUES AND BEHAVIOURS IN ROMANIAN COMMERCIALS
}

\section{Elena-Maria EMANDI}

Logos Universality Mentality Education Novelty, Section:

Social Sciences, 2014, Year III, Issue 1, pp: 57-67

Published by:
Lumen Publishing House
On behalf of:
Lumen Research Center in Social and Humanistic Sciences 


\title{
Values and Behaviours in Romanian Commercials
}

\section{Elena-Maria EMANDI}

\begin{abstract}
The impact of commercials on potential consumers is due to the complexity of the codes used. We can therefore detect a message transmitted through various signs (word, sound, visual image), visual communication containing the three types of signs as they were designated by Charles Sanders Pierce. The aim of our work is to highlight through semio-stylistic analysis values and behaviours appearing in Romanian commercials.
\end{abstract}

\section{Keywords}

Commercial, Message, Signs, Values, Behaviours, Semio-stylistic analysis.

${ }^{1}$ PhD Lecturer, "Ştefan cel Mare” University of Suceava, Romania, maria.emandi@gmail.com.

EMANDI, E-M. (2014). Values and Behaviours in Romanian Commercials. Logos Universality Mentality Education Novelty, Section: Social Sciemces, Year III, Issue 1, 2014, pp. 57-67 


\section{Introduction}

"Not everything that can be counted counts, and not everything that counts can be counted." (Albert Einstein)

Commercials were defined as intelligent puzzles by Jennifer Greatrex when referring to Angela Goddart's book The Language of Advertising. (2002, p. 18) This assertion, which synthesizes the psychology underlying advertising, appeals to the buyer's feelings and judgment as well. Sometimes commercials are individualized in such a way that they highlight the special qualities of the object, its rhetorical appearance, and less its physical existence. As the function of advertising is to "help socialize us so that we are prepared to play our role as consumers; and as consumers we are supposed to consume more standardized goods." (Petit \& Zakon, 1962, p. 16) our tastes will be both anticipated and affected. It seems that we live in a society more inclined towards the verb "to have" rather than "to be", and the question whether commercials influence our systems of values clearly situates the advertising phenomenon in the position of a means to an end. Thus, high-level consumption is to be understood as a social goal and so the rising standard of living presented in commercials is a normal consequence of the very much emphasis placed on having rather than being, on production and mass consumption trend in nowadays society.

Watching commercials opens up gates towards numerous cross-cultural issues, towards topics concerning values and behaviours. Advertisements comprise slice-of-life situations which depict ways of thinking and acting, social matters and stereotypes. The imagery and symbolism offered by commercials transmit numerous overt and sometimes subconscious messages meant to highlight values in our society

From the sociological point of view it is perfectly normal that advertising should not be in conflict with the values system of a society. For as Petit \& Zakon (1962, p. 16) assert, "it is the values system which determines the nature and significance of social institutions like advertising, not the other way round. The value system is the most precious possession of society. It is protected against conflicting values coming in from other societies and from internal rebellion with society by institutions of social control" and clearly, advertising is such an institution. Being in the service of the values existing at a certain moment in a society, it is essential for it to survive and not to be against it. According to the same two authors, "the surest way to lose a sale and a customer is to go against the tide of what people think is right and wrong." (Petit \& Zakon, 1962, p. 16) It is essential for the existence of advertising to protect social values. What social values are precisely more present in Romanian commercials and how they are encoded / expressed is the very issue of our 
paper. The focus will be on a series of commercials considered representative for the way values and behaviours are transmitted. Both Romanian and global brands commercials running on Romanian TV channels in 2012, 2013 and the first half of 2014 will be considered.

\section{Methodology}

In this section there will be presented the method of research used in order to outline values and behaviours transmitted by commercials for Romanians. The results of the steps undertaken will also be offered.

\subsection{Purpose of the Study}

Television advertising was chosen because it is a very extensively consumed medium because, being the handiest for everybody. Being given the fact that values can get varying significance depending on the transmitter (family member, unknown person, advertisement etc), repeated access to situations conveying meanings related to family, work, country etc can be translated into concrete actions and behaviours of the receivers/viewers.

\subsection{Research Methods and Findings}

The research method used in this paper is in accordance with the complexity of commercials, which are audio-video products. The selection of the advertisements didn't take into consideration whether they were dedicated to local brands or to global ones. The main criterion takes into account the presence of as clear as possible messages conveyed by a mixed semiological structure (the commercial), which appears as a vague and unstable hybrid due to a free proportioning of text and image and also due to the diversity of its components. (Adam, 1997, p. 91) Such features allow a more comprehensive approach: the verbal expressivity is doubled by the visual one. The semiotic approach can therefore go hand in hand with the stylistic investigation.

Some questions will be answered throughout the present research. The answers to these questions will be organized and will be used to check some hypotheses:

- in a society interested to over-stimulate consumption commercials convey values that favour the concept of "having" rather than "being";

- commercials encode messages according to which appearance or power turn out to be higher values than responsibility, somehow backing up the principle according to which the end justify the means;

there exists a balance between the values and false values transmitted through commercials watched by Romanians on TV. 


\subsection{Values and Behaviours in Advertising}

\subsubsection{Values}

As a social system, any culture shares a series of values that allow social expectations and collective awareness of the good, the beautiful, the moral etc. (Nerlich, 1989, p. 166) Generally speaking, values can be divided into universal ones and the others which can be divided according to the criterion of positioning individuals in society. So, respect, responsibility, solidarity, honesty and tolerance can be referred to as universal values. With a view to particularize them, one can distinguish between personal, family, social-cultural, material, spiritual and moral values.

An important category of values is represented by the individualistic ones: they attach weight to the self, more than to anything else. They appear transmitted by commercials every time the issue of freedom and the right of any person to decide what is good or bad for them is considered. Family values are also present in advertisements, the family being a system where the interest of each member is protected by unwritten laws and where each member seems to have its share in the effort meant to bring balance, well-being and comfort. Roles are clearly attributed: the mother is the protector of the nest, she takes care of the house and of the children. She is expected to cook food and rear children; the father earns money and is the protective instance, being the strongest member of the family. (www.sagepub.com/upm-data/17521 Chapter 5.pdf)

Waterman (2003, p. 108) mentions Folbre's definition of family values: "love, obligation, and reciprocity. Members of a family care about other members' welfare and happiness. They devote a certain amount of mental, physical, and spiritual resources to those other individuals to maintain both the group and the members. In turn, it is expected that other family members will do the same." The spiritual values are often attributed to divinity and they include love, truth, justice and compassion. They unite all the people in the world and they can be included in the more comprehensive set of moral values that are transmitted by each generation to the next one. The counterpart of the spiritual values, the material ones, are related to the basic needs of the human beings, such as nourishment, items of clothing and protection. They come into contradiction with the spiritual ones only when they are exacerbated, otherwise they are related to the fundamental needs of a person. The national values belong to the larger category of social-cultural values and they refer to a country's tradition, history and people. Professional values are appealed as well whenever the message of the advertisements evokes concepts such as success, teamwork, cooperation and camaraderie, honesty, integrity, respect, trust and support. 
The transmission of such values through advertisements can be highlighted through the analysis of the semiotic and rhetorical structure, taking into account the fact that the manner in which a statement is expressed may be more important than its content.

\subsubsection{Advertising and Behaviour}

As a more and more important number of products are appearing on the market, it is natural that the necessity to increase the sales should be reflected in the number of commercials that popularize them. Many media including radio commercials, billboard and internet advertisements, television and newspapers entice people of all ages to buy products. Television is a complex medium involving audio and video contact with the receiver, becoming one of the most enjoyable media. It has an important impact on viewers, offering patterns of behaviours, transmitting messages referring to the value system of the target audience. (Shimp, 2000) In nowadays society advertisements influence people as far as the way they understand life, the world and themselves, their values and their choices of bahaviour are concerned. As systems of signs, commercials spread meanings and they can serve as a true lexicon of existing cultural significances. Semiotic studies try to disclose how such commercial function, especially that all their meanings are encoded.

A social phenomenon, advertising plays an influential role in contemporary society, notably in the way a market economy operates, becoming more and more widespread every day. Taking this aspect into consideration, it is expected that it should respect high ethical standards regarding to the system of values in nowadays society. A cultural phenomenon, advertising (not all, but part of it) is liked as it lightens our lives, being entertaining, informative, witty and attractive. The problem is that sometimes advertisers are selective about the types of behaviours and the values promoted, encouraging the direction towards a society governed more by the verb "to have" rather than "to be".

\subsection{Semiotics and Stylistics - Tools in Approacbing Commercials}

\subsubsection{Semiotic Approach}

Communication in advertising is done by signs, which can be words, sounds or visual images. The three types of signs as designated by Pierce (iconic, symbolic and indexical) appear in the TV commercials. Enriching the audio message, the visual one adds complexity and stirs the mind of the researcher who approaches advertisements. The visual domain plays a very important part in the economy of a commercial: "The paranoiac mechanism whereby the multiples image is released is what supplies the understanding with the key to the birth and origin of all images, the intensity of all these dominating 
the aspect of which hides the many appearances of the concrete." (Dali, 1935, p. 3)

The study of advertisements supposes the action of decoding the verbal and nonverbal signs, the framing of meaning. By doing semiotic analysis one materialize the need of "making meanings from linguistic and visual signs." (Bulut \& Yurdaişik, 2005)

Several questions will be taken into consideration with a view to achieving the aim of the present study:

1. What values appear in the selected advertisements?

2. What symbols related to values can there be found in the visual part of the advertisements?

3. In what way are the elements carrying different types of semiotic meaning related to the linguistic message?

\subsubsection{Stylistic Approach}

Although the visual content of a commercial is said to have a very important impact on the receiver, language has its role in helping people identify and keep in mind a message or a product. Stylistic analysis in this situation means identifying patterns of usage in speech and writing (Wales, 1989). Using the art of language in commercials is meant to persuade potential buyers, transmitting in various degrees of encoding messages about values, behaviours etc. The present approach considers the three levels of stylistic analysis: sound/graphological, semantic and syntactic. Style markers at the graphological level are mainly responsible for attracting the audience. From the phonological point of view, the slogan rhyming with the brand name may be an example of catching the viewer's attention. At the lexical/semantic level, the usage of affirmative and praising words is intended to allure customers as well (Turner, 1973). Finally, at the syntactic and grammar level, details are given using complex and compound sentences. Attention is caught by the use of interrogations, while the usage of present tense indicates good quality of the advertised products and its long-lasting effect $(\mathrm{Li}, 2009)$.

\subsection{Findings}

Our study involved a number of 100 both Romanian and international brands commercials running on Romanian TV Channels during the last three years (2012, 2013, the first 9 months of 2014). Sometimes the same brand (such Dr Oetker, Hochland, Nivea etc) is present with more advertisements for different products.

Our approach confirmed the following hypotheses: daily goods (food and drink) transmit messages about professional values (excellence, teamwork, success, cooperation: the advertisement for "sliced and cleverly packed" Hochland hard cheese for example). Hochland hard cheese is a product that 
combines the good quality of the Romanian milk (national value - patriotism) and the rigor of the German technology (connoting values such as confirmed professionalism, seriousness). The commercial also promotes family values, as the protagonists are a family who are in the kitchen, playing a game: one of the two children has his eyes tied and is supposed to guess what his sister is offering him to taste. After several misses, he successfully recognizes the taste of Hochland hard cheese: the voice-over renders the qualities of the product by using a rhymed definition: "milky, creamy, tasty" ("lăptos, cremos, gustos"), thus making it more memorable. Although rhyming is not an indicator of accuracy of the truthfulness of the product's qualities, they possess a greater processing potential. People can more easily remember and mentally process such advertisements: what really matters is for receivers to find commercials fluent and easy to process. The slogan "Hochland - The Joy of Taste" (Hochland - Bucuria Gustului) connotes values such as respect for the consumer, respect of the consumers for themselves, and, in the light of the entire commercial clip respect for family values: love, care, commitment. Alcoholic drinks such as Ciucaş beer promote beside professional values (reflected in the care for the produces used in preparing their drink: the voiceover presents the ingredients - browned malt, flavoured hop, fresh water) national-ecological ones: the image is built around Cornel, the stag from Ciucaş Clearing, a symbol of the harmonious interlacing of nature, the place where the beer originates in. Friendship and harmony are also values proposed by this commercial: the product is nature's favourite beer. The personification of the stag and of nature itself is a device very frequently used by advertisers meant to attract the audience's attention and warm-heartedness. The human characteristics transferred to the stag (the stag is able to speak and think, smile) and to nature (it prefers a certain kind of beer) appeal to the emotional side of the receiver's profile. At the paradigmatic level, the choice of a stag for the role of friend is in line with the traditional male companion with whom beer is drunk. Ciucaş beer is therefore for men, not for women. This idea is reinforced by the images in the Ciucaş Clearing, where the protagonist, representative of the target audience, has some memorable moments in the company of friends, drinking a glass of natural blonde beer. This escape in nature together with friends is illustrative of some other value connoted by this advertisement: freedom and the right to choose what is good for oneself. This beer is thus associated by the receiver with the idea of magic moments of relaxation in nature surrounded by a pleasant company.

The verbal message of the ads in discussion is delivered in Romanian. One of the few foreign word that appears in one of them is "merci", a French word, used for a German chocolate bar brand, contradicting the general belief that English is most appreciated by ad consumers due to the positive associations and stereotypes (Horniks, et al., 2010). In this case, French 
refinement underlies the consideration and appreciation message of offering the individually wrapped chocolate box.

The paradigmatic choice of the image of the perfect grandmother is in line with the traditional role of women as nurturers of children. The values transmitted by this advertisement are mainly family values: love, care, indebtedness and respect. Nevertheless, professional values are rendered evident in the voice-over's presentation of the product.

The language is used to reinforce the filmed sequence: a grandson comes to his grandma who has just finished sowing a T-shirt for him. The boy turns to his mother very excited. The next scene represents the climax: the grandson offers his grandma a box of "Merci" chocolate. The last scene represents the boy's mother embracing the grandmother as a token of her thankfulness and indebtedness. Both of them look at each other and at the box of chocolate and smile. The voice over speaks about the quality of the product advertised. The dominant lexical set is that of refinement ("pleasure to choose", "unique collection") and high quality ("fine chocolate"). There are more visual images than written captions due to the fact that pictures speak for themselves, having the ability to communicate the mood.

The audio content of each commercial, including what was said by/to and/or about each of the protagonist/product helps the coding of traits. The lyrics of the song in the Merci advert suggest the close relationship between people who offer and those who receive such a product: the second person singular of the verb "to be" and of the personal pronoun connote a close relationship based on love and appreciation.

Colour plays a significant role in the syntagmatic structure of the commercials. A specific color may occur many times, linking different paradigms together with a view to obtaining a syntagm that has continuity. Color contains a rich symbolic significance, as it can be used to nonverbally and inexplicitly link concepts together (Lacey, 1998). The recurring color in Merci commercial (red on a white background) can be read as standing for love, devotedness, but it can also be deciphered as a means of drawing attention to an extremely good food product. This color appears on the T-shirt (red and white strips), on the wrapper of the individual chocolate bar; on the box of chocolate and, last but not least, on the heart-shaped dot.

The commercial for Napolact hard cheese and for Ardealul vegetal pâté have male protagonists and the message of their story speaks about values like patriotism, respect for tradition, professional excellence. If women appear giving advice (as in Dry Cooker ad), it is men who appear more frequently as experts. The exception seems to be the grandmother in the oil commercial (Oil from Grandmother - Untdelemn de la bunica) and the woman in Covalact products ads. Females appear sometimes viewed as motherly (Merci, Jacobs coffee, Oil from Grandmother), and males appear authoritative and dignified 
(Timişoreana 2012, Ardealul Vegetal Pâté), all these commercials transmitting family values in accordance with a patriarchal society.

Values related to a sound life style appear in commercials dedicated to food, but also to devices and products for a healthy and good-looking body. Nowadays culture encourages very much such values - sometimes one cannot help wondering whether the way one looks can prevail over who and what one is. Health related values refer to three different aspects: mental health, physical health and social health. Such values appear in commercials for medicines (physical health: Kebene Plus, Panadol Extra, Diclac Gel, Aspenter, Proenzi, Exoderil, Prostamol Uno, Nurofen Forte, Artrocalcium, Magnevie sleep well), tools and devices (Blend a Med 3D Expert toothbrush, Oral B toothbrush, Fixodent Plus), shampoos and beauty products (Dove - for a beautiful armpit skin, Vichy, Garnier BB Cream, Wash and Go Shampoo, L'Oreal Arginine X 3 Shampoo, Gilettte products, Nivea products, Syos products), household products (lavetesalopete.ro, Barrier windows, Structo Plus cement, Ceresit products for tiles, Whirlpool washing machine, the new Cocolino Creation, Spor Washable Dye etc).

Beside material values, spiritual values appear in commercials such as Cosmote "War Hero", which somehow subverts the viewer's expectation: it opens with the image of some young men grouped near their friends sitting on a bench. They are relaxed and have fun and one of them is pushed by another one. He trips up an old man with a cane and a bunch of flowers who was going past them. The eyes of the old man meet those of the young man in green Tshirt. The latter follows him and sees him taking the flowers to a monument. In that moment he uses his mobile phone and finds out the man's story. The old man is the protagonist of the advertisement. He connotes experience and respectability. Nevertheless, the young man with a green T-shirt is the one who deciphers the code: he surfs the net on his phone and finds out the story of the old man: he is a hero. The next day the same group of young men greet the hero with a crisp salute. This is the story: the message is encoded in the written text that appears on the screen at the end of the commercial: "Untold stories must be discovered". The next image presents details about the services offered by Cosmote. The first line in this image with useful details for the prospective purchasers is linked to the message of the ad: "Connect to them!". At the lexical level, the paradigmatic choice of the verb "to connect" foreshadows one of the services advertised (internet connection), the underlying idea being that of necessity to have such services. The details concerning the various services offered by Cosmote appear in a box that represents the outline of a mobile phone. Every message is made up of two levels of meaning: the surface and the deep level. The second one is called by R. Barthes "a coded iconic, or symbolic message" (Dyer, 1982). At the surface level, the viewer understands the type of product advertised. The connotation of this image renders evident the 
complexity of the product: it is vital to anyone who wants to understand the world around.

An important number of commercials place emphasis on individualistic values: uniqueness (Mobexpert whose slogan is "We are all different. Fortunately.", Golden Brau beer), freedom, the right to decide what is good or bad for ourselves. In the same category can be placed the advertisements that invite to experience (the new 5 Chewing Gum whose slogan is "Stimuli for senses", Orange Postpaid, H\&M, Ursus beer, Cosmote phone card, Cocolino sensation, Vodafone 4G Ultraspeed, Telekom, the New Nissan Qashqai, Heineken, Jaguar XF).

\section{Conclusions}

The values prevailing in the commercials taken into consideration refer to respect, professionalism (success, team work, cooperation, solidarity), tradition and patriotism, family (love, care, reciprocity), individual rights (freedom, right to choose what one thinks it is good for themselves) and also material values referring to basic needs of human beings. Although it is difficult to assign values to certain product categories advertised, they generally combine two or even three messages related to values in contemporary society. There appear a great variety of symbols related to the already mentioned values, starting with colours and shapes, graphics, and ending with gestures and words of the protagonists. The message expressed through symbols is meant to reinforce and make more prominent the written or verbal information. Brand identity is based on both visual and verbal issues whose function is to fix in the viewer's mind the uniqueness of the product. Advertisers are selective about the values presented, promoting some and inevitably ignoring others. The idea implied by a good part of the selected commercials that "having" leads to happiness and fulfilment mirrors the spiritual poverty of the contemporary society. This is the way how advertising plays its role in an economic system guided by and responsive to values that contribute to the development of humanity.

\section{References}

Adam, J.-M. (1997). L'Argumentaire Publicitaire. Paris: Nathan.

Bulut, T., Yurdaişik, A. (2005). Visual Semiotics and Interpretation in the Television Commercial. Retrieved from http://french.chass.utoronto.ca/assa/ASSA-No16/Article3en.html.

Dali, S. (1935). The Conquest of the Irrational. New York: Julien Levy.

Goddard, A. (2002). The Language of Advertising. London New York: Routledge. 
Horniks, J., van Meurs, F., de Boer, A. (2010). English or a Local Language in Advertising? The Appreciation of Easy and Difficult English Slogans in the Netherlands. Journal of Business Communication, vol. 47.

Lacey, N. (1998). Image and Representation: Key Concepts in Media Studies. London: Macmillan Press Ltd.

Li, M. (2009). The Stylistic Analysis of the Magazine Advertisement - Atkins Chocolate Chip Granola Bar. Asian Social Science, 5.

Nerlich, G. (1989). Speculations on the Ethical Life of Persons. Oxford: Claredon Press.

Petit, T. A., \& Zakon, A. (1962). Advertising and Social Values. Journal of Marketing, 26 (October), 15-17.

Shimp, T. A. (2000). Advertising and Promotion. Fort Worth: Dryden.

Turner, G. W. (1973). Stylistics. Harmondsworth, Middlesex: Penguin.

Wales, K. A. (1989). Dictionary of Stylistics. London: Longman.

Waterman, A. M. C. (2003). Nancy Folbre and Jennifer Roback Morse on the Invisible Heart. The Independent Review, v. VII, n. 3, 443-453.

http://journalofcommunication.ro/archive2/030/rjcpr30.html

http://www.quotationspage.com/quotes/Albert_Einstein/'

http://www.sagepub.com/upm-data/17521 Chapter 5.pdf 